\title{
Time-Opening Suprapubic Catheter versus Intermittent Catheter for Male Patients with Spinal Cord Injury (Spinal Level above Level C5)
}

\author{
Hui Chen 1,2*, P. Tang³, R. B. Ou³, J. W. Zeng², M. P. Huang1, Q. L. Liu1, Q. Q. Li', J. B. Huang1, T. H. Huang1, \\ Chonghe Jiang'2 ${ }^{2} \mathrm{Keji} \mathrm{Xie}^{3}$ \\ ${ }^{1}$ Department of Urology, Guangdong Provincial Work Injury Rehabilitation Hospital and Jinan University, Guangzhou, China \\ ${ }^{2}$ Department of Urology, Qingyan City People's Hospital, Jinan University, Guangzhou, China \\ ${ }^{3}$ Department of Urology, Guangzhou First Municipal People’s Hospital, Guangzhou Medical University, Guangzhou, China \\ Email: *doc.chenhui @163.com
}

How to cite this paper: Chen, H., Tang, P., Ou, R.B., Zeng, J.W., Huang, M.P., Liu, Q.L., Li, Q.Q., Huang, J.B., Huang, T.H., Jiang, C.H. and Xie, K.J. (2016) TimeOpening Suprapubic Catheter versus Intermittent Catheter for Male Patients with Spinal Cord Injury (Spinal Level above Level C5). Open Journal of Urology, 6, 154157.

http://dx.doi.org/10.4236/oju.2016.69025

Received: July 29, 2016

Accepted: September 17, 2016

Published: September 22, 2016

Copyright $\odot 2016$ by authors and Scientific Research Publishing Inc. This work is licensed under the Creative Commons Attribution International License (CC BY 4.0).

http://creativecommons.org/licenses/by/4.0/

\section{Abstract}

Objective: To compare the short-time complications associated with time-opening suprapubic catheter (SPT) versus intermittent catheter (IC) in male patients with spinal cord injury (above level C5). Methods: A prospective review of records was carried out to identify SCI patients managed with SPT or IC between 2011 and 2016. The complications included renal function (Serum creatinine), urinary tract infection (UTI), bladder stones, urethral complications, scrotal, and gross hematuria. $\mathrm{Pa}$ tients were followed at week 4, 3 and 6 months; the urodynamic assessment was repeated at 6 months. Results: A total of 30 patients (11 SPT, 19 IC) were recruited in this trial. There is no significant difference between the two catheter groups for the entire outcome. Scrotal abscesses and urethral stricture were only seen in patients with IC. Conclusions: SPT has similar urological complication with IC for SCI patients (above level C5) except the incidence of scrotal abscesses and urethral stricture.

\section{Keywords}

Suprapubic Catheter, Intermittent Catheter, Spinal Cord Injury

\section{Introduction}

Intermittent catheterization (IC) is the preferred management for neuro-urological patients who cannot effectively empty their bladders [1] [2]. The most common spinal level to be injured in China was cervical (31.4\% - 38.9\%) [3]. For most of these patients, they can not perform IC due to hand handicap. Suprapubic catheter (SPT) is consi- 
dered a routine procedure. However, to our knowledge, it is not clear time-opening suprapubic catheter has the least morbidity for the SCI patient. Therefore, the objective of this study was to compare urological complications of time-opening suprapubic catheter for SCI.

\section{Materials and Methods}

This study was conducted in the department of urology of three hospitals from 2011 to June 2016. A total of 30 Chronic SCI inpatients (11 SPT, 19 IC) were included. The outcome for urological complications including renal function (Serum creatinine), symptomatic urinary tract infection (UTI), bladder stones, urethral complications, scrotal abscess, and gross hematuria. Patients were followed at 1, 3, 6, 9 and 12 months. The study was approved by each hospital's Ethics Commitee. Statistical analysis was completed using a Chi-square test and Fisher's exact test to compare specific complications between the two catheter groups. A P value of 0.05 or less was considered statistically significant.

\section{Results}

At baseline, there were no significant differences between the two groups with respect to demographic characteristics (Table 1). As listed in Table 2, 27.3\% of patients in the SPT group and $31.57 \%$ of patients with an IC had at least one symptomatic UTI. Gross hematuria was noted in $54.5 \%$ of patients with SPT and in $73.7 \%$ of patients with an IC. (Table 3) For the SPT group, the incidence of recurrent bladder stones was 9.09\%, as opposed to the IC group, for which it was $5.26 \%$. In our study, scrotal abscesses and urethral stricture were only observed in patients with IC. No significant difference for average serum creatinine between SPT and IC groups at baseline and 12 months, respectively.

Table 1. Baseline patients characteristics.

\begin{tabular}{|c|c|c|c|}
\hline Parameter & SPT group $\mathrm{n}=11$ & IC group $\mathrm{n}=19$ & P Value \\
\hline $\operatorname{Age}^{*}, \mathrm{yr}$ & $34.19(12.74)$ & $35.62(11.75)$ & 0.73 \\
\hline Weight ${ }^{\star}, \mathrm{kg}$ & $60.72(26.31)$ & $61.81(25.04)$ & 0.82 \\
\hline Time since $\mathrm{SCI}^{*}$, months & $15.62(4.86)$ & $14.96(5.17)$ & 0.77 \\
\hline AIS ${ }^{* *}, \mathrm{~A} / \mathrm{B}$ & $8 / 3$ & $15 / 4$ & 0.69 \\
\hline
\end{tabular}

${ }^{*}$ Values are given as mean \pm standard deviation; $\mathrm{P}$ values from Student's $\mathrm{t}$-test between the two groups. ${ }^{* *}$ Values are given as $\mathrm{n}(\%)$; P values from Chi-square test between the two groups.

Table 2. Serum creatinine at baseline and 12 months.

\begin{tabular}{cccc}
\hline Serum creatinine, umol/L & SPT $(\mathrm{n}=11)$ & IC $(\mathrm{n}=19)$ & P Value \\
\hline Baseline & $63.18 \pm 28.34$ & $64.67 \pm 29.16$ & 0.89 \\
12 months & $69.41 \pm 22.08$ & $64.33 \pm 20.49$ & 0.53 \\
\hline
\end{tabular}


Table 3. Complications of time-opening SPT and IC.

\begin{tabular}{cccc}
\hline Complication & SPT $(\mathrm{n}=11)$ & IC $(\mathrm{n}=19)$ & P Value \\
\hline Symptomatic UTI & $3(27.3 \%)$ & $6(31.57 \%)$ & 0.81 \\
Gross hematuria & $6(54.5 \%)$ & $14(73.7 \%)$ & 0.28 \\
Bladder stones & $1(9.09 \%)$ & $1(5.26 \%)$ & 0.69 \\
Scrotal abscess & 0 & $4(31.57 \%)$ & 0.11 \\
Urethral stricture & 0 & $2(10.52 \%)$ & 0.27 \\
\hline
\end{tabular}

$\mathrm{UTI}=$ urinary tract infection.

\section{Discussion}

In SCI patients CIC is considered to be the gold standard as the most appropriate and safest bladder management method in terms of urologic complications [2]. However, the rate of CIC reverting to urethral indwelling catheter was $21.4 \%$ and $9.77 \%$ SCI patients changed their bladder management from UC to an SPT [4] [5]. Moreever, SCI patients (above level C5) were unable to adapt IC due to hand handicap. Therefore, the aim of this retrospective review is to compare the urological complications in SCI patients managed with time-opening SPT and IC.

The primary aim in the urological treatment of SCI is to protect the function of upper urinary tract [2]. Although a more thorough analysis of serum creatinine measurements is required, the overall average serum creatinine of both time-opening SPT and IC groups suggests a preservation of renal function with either form of bladder management.

In this trial, although the follow-up period was relatively short, time-opening SPT were superior to IC with respect to complication. Specifically, no patients developed scrotal abscess and urethral stricture in SPT group. The reasons we analyzed were that an SPT avoided contact with the structures adjacent to the urethra so as to be fewer adverse events in that area [6]. Of course, the limit of our study was that patient sample size was relatively small. Therefore, with a larger number of patients, it is reasonable to expect that this would become significant.

Furthermore, our study showed that there were no statistical differences between the two groups in terms of common complications including Symptomatic UTI rates, bladder stones and gross hematuria.

\section{Conclusion}

SPT has similar urological complication with IC for SCI patients (above level C5) except the incidence of scrotal abscesses and urethral stricture.

\section{Acknowledgements}

This study was supported by: 1) Medical Scientific Research Foundation of Guangdong Province, China (grant number A2015251); 2) Traditional Chinese Medicine of Guangdong Province, China (grant number A20152037); 3) National Science \& Tech- 
nology Pillar Program (2013BAI10B02).

\section{Conflict of Interest Statement}

The authors declare no conflict of interest.

\section{References}

[1] Guttmann, L., et al. (1966) The Value of Intermittent Catheterisation in the Early Management of Traumatic Paraplegia and Tetraplegia. Paraplegia, 4, 63-84. http://dx.doi.org/10.1038/sc.1966.7

[2] Groen, J., Pannek, J., Castro Diaz, D., Del Popolo, G., Gross, T., Hamid, R., et al. (2016) Summary of European Association of Urology (EAU) Guidelines on Neuro-Urology. European Urology, 69, 324-333. http://dx.doi.org/10.1016/j.eururo.2015.07.071

[3] Zhao, Y.D. and Wang, W. (2001) Neurosurgical Trauma in People's Republic of China. World Journal of Surgery, 25, 1202-1204. http://dx.doi.org/10.1007/s00268-001-0082-8

[4] Afsar, S.I., Yemisci, O.U., Cosar, S.N. and Cetin, N. (2013) Compliance with Clean Intermittent Catheterization in Spinal Cord Injury Patients: A Long-Term Follow-Up Study. Spinal Cord, 51, 645-649. http://dx.doi.org/10.1038/sc.2013.46

[5] Katsumi, H.K., Kalisvaart, J.F., Ronningen, L.D. and Hovey, R.M. (2010) Urethral versus Suprapubic Catheter: Choosing the Best Bladder Management for Male Spinal Cord Injury Patients with Indwelling Catheters. Spinal Cord, 48, 325-329. http://dx.doi.org/10.1038/sc.2009.134

[6] Ku, J.H., Jung, T.Y., Lee, J.K., Park, W.H. and Shim, H.B. (2006) Influence of Bladder Management on Epididymo-Orchitis in Patients with Spinal Cord Injury: Clean Intermittent Catheterization Is a Risk Factor for Spididymo-Orchitis. Spinal Cord, 44, 165. http://dx.doi.org/10.1038/sj.sc.3101825

Submit or recommend next manuscript to SCIRP and we will provide best service for you:

Accepting pre-submission inquiries through Email, Facebook, LinkedIn, Twitter, etc. A wide selection of journals (inclusive of 9 subjects, more than 200 journals)

Providing 24-hour high-quality service

User-friendly online submission system

Fair and swift peer-review system

Efficient typesetting and proofreading procedure

Display of the result of downloads and visits, as well as the number of cited articles

Maximum dissemination of your research work

Submit your manuscript at: http://papersubmission.scirp.org/

Or contact oju@scirp.org 